\title{
Comunicação de notícias difíceis na formação do estudante de Medicina: uma experiência utilizando o psicodrama
}

\author{
Breaking bad news in medical student training: an experience using Psychodrama
}

Maria Dulce Santiago de Carvalho' (1) | mdulcesantiago@hotmail.com

\section{RESUMO}

Introdução: Caracterizada como uma das tarefas mais difíceis enfrentadas pelos profissionais de saúde, a comunicação de notícias difíceis se revela como um assunto indispensável na formação do médico, tanto no que se refere às habilidades técnicas como essencialmente às competências humanas. Nesse contexto desafiador, surge a questão:"Em que medida os estudantes de Medicina estão preparados para lidar com essa temática?".

Relato de experiência: Tomando o protocolo SPIKES como manejo técnico associado à metodologia psicodramática, o estudo apresenta uma situação hipotético-prática na formação médica em uma instituição do interior de Minas Gerais, objetivando relatar e analisar a experiência da utilização da metodologia psicodramática na educação médica.

Discussão: O deslocar-se de seu papel para experimentar o outro lado - o papel de paciente - fez com que os estudantes vivenciassem maior sensibilidade na relação profissional, ao mesmo tempo que facilitou a assimilação de estratégias adequadas no manejo da comunicação de uma notícia difícil.

Conclusão: Os estudantes foram conduzidos a uma maior reflexão do papel do Médico, incorporando técnicas para além das habilidades biomédicas e se encontrando mais bem preparados para lidar com questões desafiadoras em sua prática profissional.

Palavras-chave: Psicodrama; Desempenho de Papéis; Educação Médica; Relação Médico-Paciente; Comunicação em Saúde.

\section{ABSTRACT}

Introduction: Considered as one of the most challenging tasks faced by health professionals, breaking bad news proves to be an indispensable subject in the training of doctors, both in terms of technical skills and essentially human skills. In this challenging context, the question arises: are medical students prepared to deal with this issue?

Experience report: Taking the SPIKES protocol as technical management associated with psychodramatic methodology, the study presents a hypothetical-practical situation in medical training at an institution in Minas Gerais, aiming to report and analyze the experience of using psychodramatic methodology in medical school.

Discussion: The shift from their role to experience the other side - the role of the patient - exposed the students to an experience of greater sensitivity in the professional relationship, while facilitating the assimilation of appropriate strategies in handling the breaking of bad news.

Conclusion: Students were led to reflecting more deeply on the role of the Physician, incorporating techniques beyond biomedical skills and finding themselves better prepared to deal with challenging issues in their professional practice.

Keywords: Psychodrama; Role Playing; Medical Education; Physician-Patient Relations; Health Communication.

${ }^{1}$ Centro Universitário Presidente Tancredo de Almeida Neves, São João del Rei, Minas Gerais, Brasil.

Editora-chefe: Rosiane Viana Zuza Diniz.

Editora associada: Cristiane Barelli.

Recebido em 08/12/21; Aceito em 11/01/22.

Avaliado pelo processo de double blind review. 


\section{INTRODUÇÃO}

Vivemos rodeados de jovens que sonham em ser médicos. Numa sociedade em que ser médico é bem diferente de ser formado em medicina, somos levados a refletir sobre o verdadeiro papel desse profissional, uma vez que querer não implica necessariamente ser médico. Desse modo, ao longo da disciplina Habilidades e Atitudes Médicas VI (HAM VI) do curso de Medicina do Centro Universitário Presidente Tancredo de Almeida Neves (Uniptan) são proporcionados ao estudante conteúdos teórico-vivenciais que envolvem desde o autoconhecimento e a identidade profissional até o cuidado na relação médico-paciente, pautado numa perspectiva fenomenológico-existencial.

O que adianta saber, mas não (saber) ser? Na trajetória de sua vida acadêmica, o estudante de Medicina se depara com o momento em que é convocado a refletir sobre seu papel profissional e como ele próprio percebe que tem se constituído como tal. A partir da reflexão entre médico e Médico, o estudante internaliza a diferença entre esses dois termos e assume com qual deles se identifica ou quer vir a se tornar em sua vida profissional: se quer apenas tratar o paciente, em um modelo robotizado e tecnicista, enxergando a doença; ou se quer ser o verdadeiro médico, aquele que escuta, que é sensível ao sofrimento do outro, enxergando o ser humano doente, e não apenas a doença.

Em vista dessas proposições, é abordada, no conteúdo programático da disciplina, a temática comunicação de más notícias - uma das tarefas mais difíceis ${ }^{1}$ e frequentes enfrentadas pelos profissionais de saúde, que requer treinamento de técnicas e habilidades de comunicação. Sem o devido preparo, o profissional tem dificuldade em se conectar emocionalmente com o paciente, gerando bloqueios. Ter competências humanas diante dessa responsabilidade implica ser sensível à dor do paciente e estabelecer uma relação de confiança, oferecendo a ele, paradoxalmente, certo conforto dentro de seu desconforto. Infelizmente, no currículo das escolas médicas, nem sempre o preparo para essa missão se encontra presente; por isso, o estudante se depara com suas fragilidades e seus temores - uma tarefa também dolorosa para ele. É comum relatarem estresse e desconforto em abordar, comunicar e discutir notícias que impactam negativamente a vida de seus pacientes.

Nesse viés, Buckman² define má notícia como "qualquer informação que afeta seriamente e de forma adversa a visão de um indivíduo sobre seu futuro" (p. 15, tradução nossa). Há médicos que têm adotado a expressão "notícias difíceis" em detrimento de "má notícia", uma vez que esta tende a carregar, com maior intensidade, uma conotação dolorosa, de muito sofrimento. Geralmente, uma notícia difícil é associada ao diagnóstico de uma doença terminal, mas envolve ainda o contexto psicossocial do paciente, como a necessidade de cirurgia cardíaca na semana do casamento da filha ou um diagnóstico que é incompatível com o emprego ${ }^{1,3}$.

Como aponta Pereira ${ }^{4}$, grande parte dos pacientes prefere receber informações claras e honestas sobre sua saúde. Ainda que nos deparemos atualmente com profissionais que omitem diagnósticos e informações ao paciente ${ }^{4}$, a verdade é imperativa; transmitir a notícia de forma compreensível e humana ajuda o paciente a se conscientizar do que se passa com ele e facilita a adesão e o engajamento no plano de tratamento.

O psicodrama, associado à utilização do protocolo SPIKES, entra em cena como o fio condutor metodológico desse ensino-aprendizagem. Em sua vertente pedagógica, no âmbito da formação médica, o psicodrama conduz o futuro médico a visualizar o paciente em seu contexto social, aprofundandose em sua vida emocional e ensaiando formas de linguagem e comunicação mais apropriadas para entender e ser entendido. Numa atmosfera lúdica, utilizando recursos dramáticos como o role-playing, o objetivo consiste em desenvolver competências humanísticas na relação com o paciente e a sensibilidade ao sofrimento do outro. O contexto da comunicação de uma notícia difícil requer que o estudante experimente o outro lado - o lugar do paciente -, uma vez que é a vivência desse papel que o torna sensível à sua dor e possibilita uma verdadeira relação de cuidado. A partir da compreensão do sentido de empatia, diálogo, tele ("dupla empatia", isto é, a empatia ocorrendo nas duas direções, em que ambos conseguem se reconhecer, sentir e perceber o outro mutuamente) e encontro trabalhados ao longo da disciplina, foram criadas cenas, com situações diversas a serem dramatizadas (perdas, doenças graves ou degenerativas etc.), envolvendo a comunicação de uma notícia ruim, o que ampliava sua sensibilidade ao mesmo tempo que oferecia aprendizado de técnicas adequadas no manejo da comunicação de uma notícia difícil.

\section{RELATO DE EXPERIÊNCIA}

Durante a docência, a partir do ano de 2018, no curso de Medicina do Uniptan, foram ministrados pela presente autora conteúdos teóricos a respeito da relação e da comunicação com o paciente, incorporando a temática "notícias difíceis", que puderam ser enriquecidos com a vivência prática.

A instituição tem como fundamento o ensino por meio de uma metodologia ativa e integrada, e, no curso de Medicina, foi possível utilizar o psicodrama como método no processo ensino-aprendizagem.

\section{O psicodrama como metodologia ativa de ensino}

Em tempos em que o cenário educacional chama a atenção da comunidade escolar para modificar parâmetros engessados 
no método ensino-aprendizagem, as metodologias ativas de aprendizagem despontam como possibilidade de quebra de paradigmas e conservas. A partir de formas inovadoras de ensinar, de maneira dinâmica e interativa, o professor se desloca do papel de detentor do conhecimento e único responsável pelo aprendizado do aluno para que este seja corresponsável por seu processo de aprendizagem. Guiado pela reflexão "fazer para aprofundar o saber", o professor incentiva a autonomia e o protagonismo do aluno, favorecendo que ele deixe de ser passivo e se torne ativo na construção do conhecimento.

Ao lançar mão de metodologias ativas, como jogos, gamificação, team based-learning, aprendizagem baseada em problemas, sala de aula invertida, entre outros, o professor promove e provoca o envolvimento do aluno, alcançando resultados significativos na incorporação de conteúdos e vivências.

É nesse cenário que se insere o psicodrama como método ativo de ensino; por meio de recursos lúdicos e teatrais, o estudante entra em cena como participante ativo na construção de sua aprendizagem e na formação do ser médico. No contexto psicodramático, o homem é percebido e entendido como um ser de ação, com potencial criativo, sendo possível, por meio de suas técnicas teatrais, (re)experienciar e (re)criar relações. Criado pelo médico Jacob Levy Moreno ${ }^{5}$, que expressava que a escola deveria romper com o universo mecânico de ensino-aprendizagem, o psicodrama, em sua dimensão pedagógica, parte de estratégias que visam promover a espontaneidade e a criatividade. Como um método de ação, o psicodrama associa a arte com o aprendizado, articulando a incorporação de conteúdos e vivências com a construção e a ressignificação do papel profissional. Suas ferramentas são envoltas pelo caráter lúdico que promovem a imaginação e favorecem o desdobramento criativo dos estudantes em ousar e em fazer o novo. Os objetivos se assentam na transmissão de um assunto novo, na assimilação de conteúdo já conhecido ou mesmo para desbloquear a criatividade. Por meio de recursos, em que o jogo dramático e o role-playing se inserem, utilizando as técnicas psicodramáticas, o professordiretor guia os estudantes, empregando dramatizações, as quais visam à compreensão ou ao aprofundamento de conceitos e ao treino do papel profissional.

À luz do psicodrama como método ativo de ensino, Liberali et al. ${ }^{6}$ ressaltam que o conhecimento é construído pela ação; em termos psicodramáticos a dramatiza-ação permite ao estudante ampliar a visão sobre si e sua realidade, e transcender o conhecimento para sua prática ${ }^{7}$, o que alavanca seu papel profissional. O psicodrama pedagógico ou método educacional psicodramático proposto por Romaña $a^{8-10}$ fornece um conjunto de estratégias valiosas ao processo de ensino na medida em que aproxima a experiência de vida à aprendizagem educacional, utilizando a dramatização como recurso no palco do como se, em que o estudante pode atuar angústias, dúvidas, medos e ansiedade presentes em seu papel profissional. Nesse viés, diante de circunstâncias imaginárias semelhantes a situações reais, o estudante de Medicina é estimulado a experimentar, treinar e assimilar novas atitudes e outros olhares sobre as situações que enfrentará no cotidiano médico, transitando pelo role-taking (adoção de um papel acabado e estabelecido, é o primeiro papel que o estudante assume) e pelo role-playing (jogando com mais liberdade seu papel profissional de médico, no "como se"), e alcançando o role-creating (criação do papel), que implica a vivência criativa de seu papel profissional ${ }^{11}$.

\section{Cuidado versus cuidado: ser-com}

Na formação do papel profissional, é necessário que o estudante de Medicina desenvolva habilidades e atitudes. Mas ser médico é muito mais do que aprender técnicas; é uma arte de conhecer o outro.

Tendo como fio condutor a vicissitude entre os termos médico e Médico, paralelamente relacionados, seguimos respectivamente também pela distinção entre cuidado e Cuidado. O primeiro, aqui designado com inicial minúscula, encontra-se voltado ao cuidado em saúde, mas no sentido de tratar a doença. O segundo, com inicial maiúscula, concebe o cuidado no sentido existencial da experiência do adoecimento ${ }^{12}$. Abordar esses conceitos nos dirige à filosofia fenomenológicoexistencial, percebendo e visualizando o paciente como um ser-no mundo (Dasein), o que implica compreender a existência do sujeito em sua complexidade ${ }^{13}$. Desse modo, o médico deve olhá-lo não como uma doença, mas como expressão única de uma totalidade. Em consonância com esse panorama filosófico, Souza et al. ${ }^{14}$ esclarecem que "Moreno parte de uma concepção fenomenológica de homem e de mundo e entende que um só existe em relação a outro e com sua percepção do outro" (p. 14). Nesse contexto, o estudante em formação - futuro médico - é levado a resgatar a totalidade existencial do paciente, o ser-com-a-doença, compreendendo-o em seu modo de serno-mundo contextualizado, que tem sua história de vida, seu presente e seu passado, que o tornam quem ele é.

De modo correlato, ao falarmos em Cuidado, abordamos a imprescindibilidade do encontro - o ser-com (o paciente) -, e, segundo Carvalho ${ }^{7}$, é por meio deste que o primeiro acontece, "sendo a via por onde os manejos médicos apreendidos são aplicados, estreitamente vinculados ao acolhimento, às técnicas e às modalidades de entrevista" (p. 74). Em termos da relação entre médico e paciente, cria-se, portanto, um genuíno interesse pela existência do outro, sedimentado pelo Encontro e permeado pelo Cuidado. Corroborando essas reflexões,

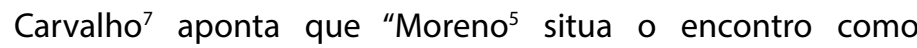


fenômeno télico em que o ser-no-mundo se manifesta por seu grau de espontaneidade e de comunicação verdadeira" (p. 74).

Contexto manifesto, presume-se que o profissional seja o Médico, e a relação perpasse pelo verdadeiro Cuidado em saúde; implica transcender um relacionamento pacientemédico mecanizado e promover o Encontro, em que o primeiro se revela para além de sua doença, na expressão de sua existência e da história de vida que o representa.

\section{O protocolo SPIKES como ferramenta na dramatização da notícia difícil}

A partir de estratégias técnicas na comunicação de notícias difíceis, optou-se por utilizar o protocolo SPIKES², o mais adotado na literatura internacional sobre o tema, como manejo técnico mesclado às habilidades relacionais trabalhadas na disciplina. No intuito de oferecer ao profissional maior segurança e aprimoramento das habilidades comunicacionais, essa ferramenta contribui para que a informação seja transmitida de maneira honesta, sem, contudo, tirar as esperanças do paciente, e auxilia na abordagem das emoções de modo que as competências humanísticas sejam desenvolvidas. Tendo em vista as dificuldades enfrentadas pelos profissionais de saúde nessa tarefa desafiadora, ele se revela como uma prática útil - uma forma especializada de treinamento de habilidades de comunicação entre médico e paciente ${ }^{3}$.

O referido protocolo (Quadro 1) constitui um modelo de seis passos que pode promover maior segurança ao médico na comunicação do diagnóstico. A intenção é que os objetivos mais importantes sejam contemplados: colher as informações a respeito do paciente, transmitir as informações médicas, acolher suas emoções, proporcionar suporte e conseguir sua adesão para que colabore no desenvolvimento de uma estratégia ou plano de tratamento para o futuro ${ }^{15}$.

Tendo o Ministério da Saúde do Brasil em conjunto com o Instituto Nacional de Câncer (Inca), com o apoio da Sociedade Beneficente Israelita Brasileira Albert Einstein ${ }^{16}$, como norteadores e respaldos teórico-técnicos, foram seguidas as etapas preconizadas no referido protocolo. Na primeira

\section{Quadro 1. Protocolo SPIKES.}

\begin{tabular}{lll} 
S & Setting up & Preparando-se para o encontro \\
P & Perception & Percebendo o paciente \\
I & Invitation & Convidando para o diálogo \\
K & Knowledge & Transmitindo as informações \\
E & Emotions & Expressando emoções \\
S & Strategy and Summary & $\begin{array}{l}\text { Resumindo e organizando } \\
\text { estratégias }\end{array}$ \\
\hline
\end{tabular}

Fonte: Retirado de Lino et al. ${ }^{15}$ (p. 53). etapa (preparando-se para o encontro), o olhar do médico está voltado para si, momento em que ele avalia os próprios sentimentos e revê os dados que fundamentam a notícia ruim; é fundamental que ele se prepare e prepare também o ambiente, envolvendo privacidade e confortabilidade ao paciente e aos familiares. Na segunda etapa (percebendo o paciente), antes de contar, o médico tenta perceber o que aquele já sabe de sua doença, tentando identificar expectativas, negação da doença e desinformações. Na terceira etapa (convidando para o diálogo), ele avalia seu desejo de saber, procurando entender se preferiria receber as informações de forma detalhada ou gradual, uma vez que nem sempre o que o profissional quer dizer é o que o paciente quer saber. Na quarta etapa (transmitindo a notícia e as informações), o profissional enuncia a notícia em pequenas doses, evitando a dureza excessiva, anunciando com delicadeza que não possui boas notícias. Na quinta etapa (expressando emoções e oferecendo respostas afetivas), o médico acolhe o paciente, dando voz aos sentimentos e validando as emoções. O profissional acolhe a expressão de sentimentos diversos tomando o cuidado de não antecipar a reação emocional do paciente. Cada lamento precisa ser ouvido e legitimado, isso faz a diferença. Na última etapa (traçando estratégias), o médico resume as principais questões abordadas e traça uma estratégia de enfrentamento; ambos discutem juntos o plano de tratamento e planejam o futuro averiguando de antemão se seu paciente está pronto para falar a respeito naquele momento.

Atrelado a essas estratégias técnicas, o psicodrama se configura como um método de ação profunda e transformadora que trabalha as relações interpessoais. Sob essa óptica, no âmbito da comunicação de notícias difíceis, o estudante, futuro médico, carece incorporar habilidades tanto técnicas como humanas, alicerçadas numa relação de Cuidado, desenvolvida e aprimorada durante os conteúdos teóricos-vivenciais da disciplina.

Nesse percurso, em consonância com a perspectiva fenomenológico-existencial, a abertura a um autêntico interesse em ouvir o outro lança o estudante na dimensão dialógica do encontro, fazendo surgir diante de si seu paciente ao mesmo tempo que surge diante do paciente seu médico, em que o profissional se desloca do papel exclusivo de portavoz da discursividade técnico-científica e se torna um ser-com, quando se encontra conectado com seu paciente, emergindo a afetividade nesse vínculo profissional.

Uma vez que o Cuidado em saúde precisa abranger, além dos aspectos técnicos e científicos, os preceitos éticos, filosóficos e humanísticos, comunicar uma notícia difícil envolve cuidar daquele(s) que a recebe(m). Nessa perspectiva, comunicar vai além de informar e perpassa etapas que auxiliam 
não só o profissional, mas também o paciente e seus familiares, fornecendo subsídios técnicos e emocionais que sustentam uma boa relação terapêutica.

\section{O como se: comunicando a notícia difícil}

No sentido de privilegiar os aspectos humanistas na comunicação com o paciente e promover a dimensão dialógica do encontro, as aulas tomadas pela metodologia psicodramática permitiam que os estudantes transitassem entre os papéis de médico e de paciente, de modo que no papel de médico pudessem experimentar situações próximas ao que será vivenciado ao longo de sua profissão, ao mesmo tempo que se colocarem no papel de paciente os tornaria mais sensíveis ao seu sofrimento.

Experimentar esse mundo de possibilidades permite a entrada no como se e o coloca confrontado perante a circunstância da realidade vivenciada por quem está do outro lado. A ideia não se encontrava focada em caracterizar as atitudes como certas ou erradas, mas em levar o estudante a desmistificar a onipotência do médico, fazendo-o perceber suas limitações e estimulando-o a desenvolver suas habilidades de modo contínuo.

Em termos de abordagem metodológica7 , o psicodrama direcionado ao ensino médico tem início com o aquecimento dos estudantes, a fim de prepará-los para a temática a ser trabalhada, e perpassa a vivência prática, inserindo-os nas atividades, fomentando discussões e reflexões, culminando com o compartilhar das experiências e com o processamento, por meio da transposição do que foi vivenciado para sua prática. Pela singularidade de trabalhar numa atmosfera lúdica e protegida do como se, criando um campo relaxado, o psicodrama favorece o aparecimento de uma atuação espontânea e criativa. Conforme explica Carvalho:

O intenso ineditismo deste trabalho ocorre na fase da dramatização, na qual os alunos são convidados a vivenciarem tanto o papel profissional quanto o de paciente. Como resultado, evidenciase o aprofundamento dos conceitos teóricos e o estabelecimento de relações mais participativas, sendo protagonistas no processo de construção de seu aprendizado (p. 76).

Para que o trabalho psicodramático se intensifique, o professor utiliza técnicas psicodramáticas, instrumentos valiosos na percepção do próprio papel, como o solilóquio (solicita aos estudantes que pensem em voz alta e deem voz aos seus pensamentos); o duplo (professor ou outro[s] estudante[s] entra[m] em cena como ego[s] auxiliar[es], posicionandose próximo[s] ao protagonista, falando como se fosse[m] ele e lançando um foco de luz para algo que ele pode não estar percebendo); espelho (o protagonista é retirado da cena e outro colega entra em seu lugar, fazendo um espelho dele, a fim de que ele possa se ver em cena, ampliando sua percepção de si e possibilitando uma visualização mais esclarecedora); e inversão de papéis (o protagonista e o ego auxiliar/contrapapel trocam de lugar).

Oego auxiliar, como um dos instrumentos do psicodrama, é aquele que faz o contrapapel ou o papel complementar, conservando-se no lugar de paciente, trazendo à tona, por meio do manejo das técnicas psicodramáticas por parte do diretor, elementos que podem estar se passando no campo subjetivo. O protagonista é o estudante que centraliza a história e que está em cena desvelando um enredo e representando um papel (específico) no contexto ensino-aprendizagem; no âmbito da Medicina, é o estudante que está treinando seu papel de médico na relação com o paciente.

$\mathrm{Na}$ trajetória da condução psicodramática, seguiramse as etapas: aquecimento (preparação para a cena e para o jogo de papéis), dramatização (a cena em si) e compartilhar (os estudantes compartilhavam suas emoções nos respectivos papéis e sentimentos suscitados). O aquecimento das cenas foi introduzido com um jogo dramático, em que os estudantes deveriam se imaginar numa sala de espera onde receberiam uma notícia. Nesse jogo proposto por Monteiro ${ }^{17}$ e adaptado pela presente autora para a aula em questão, eles deveriam criar um personagem com base na notícia recebida, reagindo conforme o fato e desenrolando uma dramatização na qual todos se interagiam com suas notícias. As cenas são articuladas fundamentalmente no intuito de promover o aquecimento e a aproximação com o conteúdo, conectando com o assunto. Em seguida, foi feita uma dramatização, espontaneamente trazida por estudantes que se sentiam aquecidos para entrar em cena. A cena contava com dois estudantes nos papéis de médico e paciente, na qual o médico precisava comunicar uma notícia difícil, norteado teoricamente pelo protocolo SPIKES. Os estudantes experimentaram ambos os papéis, e os demais colegas puderam entrar em cena fazendo duplos, espelhos, solilóquios, enriquecendo a cena e, consequentemente, a vivência prática. O professor, na função de diretor da cena, representa a figura do produtor da encenação, com a função de estimular a espontaneidade e manter os estudantes aquecidos, sendo facilitador de descobertas e aprendizado.

Como fragmento ilustrativo da cena vivenciada, foi dramatizada a comunicação que envolvia a necessidade de amputação da perna em uma paciente com diabetes. A notícia, de antemão, já havia sido capaz de lançar o estudante em um ambiente escuro e aterrador. Entretanto, ali estavam paciente e médico no palco do como se perante a vivência de uma situação dolorosa, acenando para um mundo de lamentos e sofrimento; 
logo, o que se espera é que o profissional possa ajudar a aliviar a dor que assola.

Montado o cenário, o estudante no papel de médico transita pelas etapas do protocolo SPIKES, sendo visível o papel incorporado logo na primeira fase, na qual se exige que o profissional se prepare emocionalmente, bem como ao ambiente, para o momento, fazendo solilóquios, que evocam seus sentimentos de impotência, angústia e dificuldade perante a situação. É importante ressaltar que, quando a cena era congelada pela professora/diretora, outros estudantes podiam entrar em cena e fazer seus solilóquios e duplos no papel de médico. Dando sequência à comunicação da notícia difícil, o estudante/médico acolhe a paciente em seu consultório e pergunta como está se sentindo, o que tem passado em sua cabeça nesse período e sobre os exames que haviam sido solicitados. Entra em cena outro estudante fazendo duplo e pergunta se ela havia conversado com alguém sobre seus sintomas ou se buscou na internet, o que aquece o estudante em seu papel de paciente, prosseguindo sua fala e alimentando a cena. Em seguida, o estudante/médico informa que gostaria de conversar e explicar o que pode perceber com os exames e os sintomas apresentados, questionando como a paciente gostaria de saber o que se passava com ela. A cena transcorre e ele procura comunicar a notícia em pequenas doses, mas fica paralisado, olha para os colegas e para a professora pedindo ajuda naquele momento. A professora congela a cena e solicita solilóquio, e o estudante responde: "Estou perdido... não sei como falar...." Colegas fazem duplos, sugerindo possibilidades. O estudante, no papel de médico, retoma a comunicação pelos exames que foram solicitados (ultrassonografia das pernas) e prossegue explicando que o diabetes já vem sendo tratado há bastante tempo e que reconhece o esforço dela. Com essa atitude, vai reforçando seu envolvimento no processo de tratamento, mas explica que o diabetes consiste em uma doença muito complexa e que algumas vezes tem complicações muito graves. Nesse momento, a palavra já está com a paciente que pergunta: "Eu vou morrer, doutor?" O médico prossegue informando sobre um trombo na perna que poderia comprometer a vida da paciente. Assim, paulatinamente comunica a notícia: "Infelizmente recomendo que a perna seja amputada". Dáse início então ao momento de expressão das emoções. $\mathrm{O}$ estudante, no papel de paciente, revela-se pávido e diz: "Não, não pode ser!". Após alguns instantes de silêncio em que o médico toca suas mãos, a diretora solicita a inversão de papéis para que o estudante, agora no papel de paciente, possa se sentir do outro lado, recebendo aquela notícia difícil e suas possíveis reações. Solilóquios também são feitos pela plateia, sensibilizando a todos. De volta ao seu papel de médico, ele traça estratégias de tratamento, resumindo o que foi abordado. É importante salientar que o papel de paciente vivenciado pelo outro estudante também foi experimentado e acrescentado pelos demais estudantes que se sentiam aquecidos para entrar em cena, contribuindo para a potencialização dramática.

Após a dramatização, seguiu-se o compartilhar, quando foi facilitada aos estudantes a expressão de sentimentos, impressões e aprendizado. É o momento de dividir reflexões e sensações que reverberaram em função das cenas transcorridas. As repercussões se mostraram nos rostos de todos e entoaram de forma uníssona, ressaltando a emoção e a incorporação do aprendizado e das habilidades relacionais e humanas no Cuidado com o outro.

\section{DISCUSSÃO}

Em diferentes países, outras experiências têm sido relatadas com o intuito de oferecer estratégias ou abordagem para a transmissão de uma notícia difícil e facilitar a prática médica. Ferramentas como o protocolo PACIENTE ${ }^{18}$, o modelo $\mathrm{ABCDE}^{1}$ e o protocolo SPIKES ${ }^{2}$ têm se revelado técnicas de potencial manejo. Ainda que sejam supostamente diferentes, elas se assemelham em termos de estratégias e contêm em seu âmago a preparação para a transmissão da notícia difícil, a construção e a solidificação de uma boa relação médicopaciente, a adequada comunicação da notícia ruim, o amparo e a validação emocional às reações de pacientes e familiares, e a estruturação de um plano terapêutico.

Buckman², referência norteadora na temática, aponta que, "se fizermos malfeito, pacientes e os membros familiares podem nunca nos perdoar, mas, se fizermos bem, eles nunca irão nos esquecer" (p. 209, tradução nossa). Somos conduzidos, portanto, a refletir a respeito do impacto que uma notícia difícil pode repercutir na vida do paciente e de sua família, não apenas pela notícia em si, mas substancialmente pela maneira como é comunicada. Sucupira ${ }^{19}$ salienta a importância de se construir uma proposta de ensino que juntamente com a incorporação e desenvolvimento das habilidades biomédicas priorize a formação humanística do profissional que terá como missão cuidar do sofrimento humano.

Essas ferramentas contribuem para que a informação seja transmitida de maneira honesta, sem, contudo, tirar as esperanças do paciente, e auxiliam na abordagem das emoções de modo que as competências humanísticas sejam desenvolvidas. Tendo em vista as dificuldades enfrentadas pelos profissionais de saúde nessa tarefa desafiadora, o protocolo SPIKES ${ }^{2}$ se revela como uma prática útil, sendo reforçada ainda pela pesquisa realizada por Baile et al. ${ }^{3}$ - uma forma especializada de treinamento de habilidades de comunicação médico-paciente. 
A metodologia psicodramática acena para novos rumos na educação médica em termos de incorporação de conteúdos e desenvolvimento de técnicas relacionais, sendo o conhecimento construído pela ação. Ao vivenciarem situações semelhantes às situações cotidianas, os estudantes puderam encarar desafios e experimentar possibilidades de atuação, trabalhando dúvidas e sentimentos. Estar ao lado de colegas/ atores nas cenas que foram levadas ao palco abriu caminhos para identificar diferentes possibilidades de atuação, treinar suas habilidades de comunicação e refletir sobre o verdadeiro sentido de cuidar do sofrimento humano.

Os estudantes relataram que o protocolo SPIKES, associado à metodologia do psicodrama, conduziu-os à aproximação de um tema pertinente à sua prática profissional, para a qual nem sempre estão preparados. Ao encenarem suas dificuldades e perceberem o colega em cena nos papéis dramatizados, eles puderam ampliar sua autopercepção no papel de médico, contactar as próprias emoções e manejálas de forma adequada, treinando e desenvolvendo suas competências humanas. No momento do compartilhar, emergiram expressões carregadas de sentimentos, emoções e reflexões, como de A: "Não estamos preparados para lidar com situações como essa... mas sabemos que elas vão acontecer"; de G: "Senti a dor dele em mim...”; de L.: "Eu fiquei pensando como foi receber uma notícia tão perto de mim sem esse preparo todo do profissional".

Em contrapartida, para alguns estudantes, foi complicado acessar e processar esse momento desafiador de comunicar uma notícia difícil, uma vez que, por consistir em um ambiente artificial de sala de aula, tiveram dificuldade em entrar no "como se" da representação teatral e em conectar com os próprios sentimentos. Somada a esse fato, a utilização de técnicas e recursos dramáticos mobilizou ansiedade em alguns estudantes quanto ao desempenho de papéis e ao receio da avaliação de sua atuação em cena por parte da diretoraprofessora, bloqueando uma conduta espontânea e criativa. Outro ponto importante que merece destaque se refere à inexperiência dos estudantes em lidar com suas próprias questões emocionais. Os temas e as questões trabalhados em sala faziam com que se deparassem com suas próprias fragilidades adormecidas, apontando a necessidade de a escola médica conter em seu currículo conteúdos também voltados à saúde mental do estudante de Medicina. Uma vez que, para cuidar do outro precisam cuidar de si, as instituições de ensino precisam possibilitar aos estudantes de Medicina o cuidado de si como base para a estruturação de um bom profissional e resgatar a condição humana desses profissionais.

A modo de discussão, notadamente, percebeu-se que a utilização do protocolo SPIKES associado à metodologia psicodramática viabilizou a aproximação do estudante/ futuro médico com seu paciente. O deslocar-se de seu papel para experimentar o outro lado fez com que os estudantes vivenciassem maior sensibilidade na relação profissional, ao mesmo tempo que oferecia aprendizado de técnicas adequadas no manejo da comunicação de uma notícia difícil. Norteados pelo protocolo SPIKES, eles se sentiram mais bem equipados estrategicamente na abordagem e na conduta, incorporando técnicas para além das habilidades biomédicas. Consoante com a perspectiva fenomenológico-existencial, o estudante valorizou e compreendeu o significado de um genuíno interesse pelo ser que sofre, em que, por meio da relação de Cuidado, um passa a existir diante do outro.

\section{CONSIDERAÇÕES FINAIS}

Acessar esse campo de possibilidades evidencia a contribuição da exploração das técnicas psicodramáticas para a reflexão do papel de médico e o desenvolvimento da relação com o paciente, prepara o estudante para lidar com questões desafiadoras em sua prática profissional e aponta outras possibilidades de ensino-aprendizagem. A partir do momento em que o estudante/médico se movimenta, rompendo com o papel cristalizado e engessado desse profissional, ele quebra conservas culturais e faz surgir o novo, questionando a falta de sentido de se cumprir tão mecanicamente os papéis de médico e também o de paciente.

Tendo em vista a importância do preparo acadêmico na temática da comunicação de notícias difíceis, lançar o estudante rumo ao novo, representado aqui pela reinvenção do papel profissional e pela reconstrução das práticas de saúde, implica penetrar em uma gama de reflexões pautadas na abordagem fenomenológica existencial e suscitadas pela metodologia psicodramática. Uma vez que o Cuidado é o sentido da existência humana, ele retrata também o verdadeiro profissional médico, voltado ao sentido existencial da experiência do adoecimento do paciente: o ser-com-a-doença.

A partir do mergulho na reflexão de Abel Salazar ("o médico que só sabe de Medicina nem de Medicina sabe"), abriram-se as cortinas para o estudante entrar em cena se reencontrando e se encontrando com seu paciente nas encenações levadas ao palco, em que se descobriu que ser médico é muito mais que saber teorias e técnicas, mas conseguir se conectar verdadeiramente com seu paciente, conhecendo-o em sua totalidade existencial.

No contexto da comunicação de uma notícia difícil, mediado pelo protocolo SPIKES e tomando como alicerce a metodologia psicodramática, seguiram-se os critérios de Kaufman ${ }^{20}$, indicando que os estudantes podem experimentar o outro lado, invertendo papéis com o paciente no cenário 
do como se e reproduzindo situações vividas ou imaginadas. De modo exponencial, os estudantes também ousaram fazer solilóquios, revisitaram seus mundos internos, experimentaram possibilidades ao fazerem duplos, iluminaram um caminho, talvez, antes escuro e carregado de medo e insegurança. Não que a intenção fosse banir esses sentimentos, mas saber lidar com eles, até porque acreditamos que, sem sentir, o Médico será apenas mais um formado em Medicina. E felizmente sercom, estar com esses estudantes nesse processo de eles se tornarem médicos era a verdadeira missão da disciplina.

\section{CONTRIBUIÇÃO DA AUTORA}

Maria Dulce Santiago de Carvalho participou exclusivamente de todas as atividades referentes à conceituação, investigação, metodologia, revisão e edição do artigo.

\section{CONFLITO DE INTERESSES}

Declaro não haver conflito de interesses.

\section{FINANCIAMENTO}

Declaro não haver financiamento.

\section{REFERÊNCIAS}

1. Vandekieft GK. Breaking bad news. Am Fam Physician. 2001;64(12):1975-8.

2. Buckman R. How to break bad news: a guide for health care professionals. Toronto: University of Toronto; 1992. doi: 10.3138/9781487596989.

3. Baile WF, Buckman R, Lenzi R, Glober G, Beale EA, Kudelka AP. SPIKES - a six-step protocol for delivering bad news: application to the patient with cancer. Oncologist. 2000;5(4):302-11. doi: 10.1634/theoncologist.5-4-302.

4. Pereira CR. Comunicando más notícias: Protocolo PACIENTE [tese]. Botucatu: Universidade Estadual Paulista "Júlio de Mesquita Filho"; 2010.

5. Moreno JL. Psicodrama. São Paulo: Cultrix; 1975.
6. Liberali R, Grosseman S. Use of psychodrama in medicine in Brazil: a review of the literature. Interface. 2015;19(54):561-71. doi: 10.1590/180757622014.0524.

7. Carvalho MDS. From the appointment with oneself to the meeting with your patient: psychodrama in medical training. Rev Bras Psicodrama. 2018;26(2):72-83. doi: 10.15329/2318-0498.20180028.

8. Romaña MA. Psicodrama pedagógico. Campinas: Papirus; 1987.

9. Romaña MA. Do psicodrama pedagógico à pedagogia do drama. Campinas: Papirus; 1996.

10. Romaña MA. Pedagogia do drama: 8 perguntas e 3 relatos. São Paulo: Casa do Psicólogo; 2004.

11. Calvente C. O personagem na psicoterapia: articulações psicodramáticas. São Paulo: Ágora; 2002.

12. Ayres JRCM. O cuidado, os modos de ser (do) humano e as práticas de saúde. Saúde Soc. 2004;13(3):16-29. doi: 10.1590/S0104-12902004000300003.

13. Heidegger M. Ser e tempo. Petrópolis: Vozes; 2005.

14. Souza AC, Drummond J. Sociodrama na educação. Rio de Janeiro: Wak; 2018.

15. Lino CA, Augusto KL, Oliveira RAS, Feitosa LB, Caprara A. Uso do protocolo SPIKES no ensino de habilidades em transmissão de más notícias. Rev Bras Educ Med. 2011;35(1):52-7. doi: 10.1590/S0100-55022011000100008.

16. Ministério da Saúde, Instituto Nacional de Câncer, Sociedade Beneficente Israelita Brasileira Albert Einstein. Comunicação de notícias difíceis: compartilhando desafios na atenção à saúde. Rio de Janeiro: Inca; 2010 [acesso em 25 ago 2021]. Disponível em https://www.inca.gov.br/sites/ ufu.sti.inca.local/files//media/document//comunicacao-de-noticiasdificeis-compartilhando-desafios-na-atencao-a-saude-2010.pdf.

17. Monteiro RF. O lúdico nos grupos: terapêuticos, pedagógicos e organizacionais. São Paulo: Ágora; 2012.

18. Pereira CR, Calônego MAM, Lemonica L, Barros GAM. The P-A-C-I-E-N-T-E Protocol: an instrument for breaking bad news adapted to the Brazilian medical reality. Rev Assoc Med Bras. 2017;63(1):43-9. doi: 10.1590/18069282.63.01.43.

19. Sucupira AC. A importância do ensino da relação médico-paciente e das habilidades de comunicação na formação do profissional de saúde. Interface. 2007;11(23):619-35. doi: 10.1590/S1414-32832007000300016.

20. Kaufman A. Teatro pedagógico: bastidores da iniciação médica. São Paulo: Ágora; 1992. 